\title{
A model of West African Millet Prices in Rural Markets
}

\author{
Nathaniel Higgins, Beat Hintermann and Molly Brown
}

\section{Introduction}

Predicting prices for food staples in poor regions is crucial for combating food insecurity, defined as the ability to purchase enough food to lead an active and healthy life. Food insecurity is most frequently caused by insufficient access to food instead of absolute lack of food availability. In West Africa, with its large population of poor who spend over half their income on food, the local price of food can be a significant source of food insecurity (Barrett and Maxwell, 2005). In fact, sudden increases in food prices in 2008 were coincident with a more than doubling in the number of hungry people in the world, from 820 million to more than 2 billion (FAO et al. 2011, par. 42). Improved estimates of harvests mid-season are of course an indispensable tool in predicting and combating food insecurity, but the physical presence of food in some parts of the country (e.g. the capital) may not avert a crisis in rural areas if distributional networks are not well established, resulting in a situation where food is locally scarce and thus large parts of the population are unable to afford it. Regional and local price prediction models therefore should be an important complement to aggregate food quantity forecasts. That is, we need a price forecasting model to anticipate potential changes in food security, since food security is affected by both food availability and by food prices. Until now, 
there have been no usable commodity-price forecasting models for the small, informal farmer's markets that dominate much of the Sahel.

In this article we specify a model of local millet prices in the three West African countries of Burkina Faso, Mali, and Niger. Millet is the most widely available grain in the region, and the grain most frequently purchased when farmers' own production is exhausted (Jayne et. al. 1996 and Brown 2008). Millet is popular both because it can be grown in semi-arid zones where most other crops require irrigation, and because it has high nutritional value. The area of Africa we focus our modeling on relies heavily on millet as a source of protein and calories; Burkina Faso, Mali, and Niger are three of the four largest producers of millet in the region (the fourth being Nigeria; Obilana 2003). Burkina Faso, Mali, and Niger are also countries that frequently experience food insecurity, ranking $92^{\text {nd }}, 102^{\text {nd }}$, and $91^{\text {st }}$, respectively, out of 107 countries ranked by the Global Food Security Index. ${ }^{1}$

We construct an econometric panel data model that is capable of predicting prices at the market-level across the region while controlling for unobserved heterogeneity. Using monthly millet price data from 1995 to 2006 obtained from USAID’s Famine Early Warning Systems Network (FEWS NET; May 1991; Chopak 1999) we estimate a price model for 162 rural markets over time. Prices are retail-level prices observed at various markets, including rural markets. We control for intra-annual price variation caused by

${ }^{1}$ http://foodsecurityindex.eiu.com/Country. Accessed 28 October 2013. 
imperfect storage and asymmetric integration into world markets, and for the influx of caloric substitutes such as rice. Ours is the only article we are aware of that builds a price forecasting model usable at the market-level and over such a large region, answering the need expressed by various development and early warning institutions (Beekhuis and Laouali, 2007).

In our model we account for the transmission of prices throughout a region, as local farmers and traders move their product to the markets that offer the best prices. We find that after controlling for local growing conditions, prices across the region are correlated and that the strength of this correlation decreases with distance. We calculated the contemporaneous correlation in millet prices between all markets in our sample. The average between-market correlation for those markets in the closest quartile (closer than approximately $33 \mathrm{~km}$ ) is 0.7 . The between-market correlation declines nearly linearly across the remaining quartiles, from $0.7(<33 \mathrm{~km})$ to 0.58 ( $>33 \mathrm{~km}$ and $<60 \mathrm{~km}), 0.44$ (> $60 \mathrm{~km}$ and $<100 \mathrm{~km})$, and finally $0.34(>100 \mathrm{~km})$. This is consistent with arbitrage across markets by medium to long-distance traders (Terpend, 2006).

Another novel aspect of our analysis is our use of satellite-based remote sensing data, specifically of satellite-derived Normalized Difference Vegetation Index (NDVI) from the Advanced Very High Resolution Radiometer (AVHRR), to detect and control for variation in local agricultural conditions over the period during which we have millet prices. NDVI measures the inter-annual variability of moisture conditions that affect food production on a fine scale, giving us the ability to compare local growing conditions in a given year to previous years. Since reliable agricultural production data does not 
exist at this fine spatial scale and long time period, inclusion of NDVI adds unique information to the price model. Previous research has shown that NDVI is directly related to yield (Tucker et al., 1981). This is because many of the conditions that adversely affect plant development such as drought, fertilization, precipitation events and pests also result in a corresponding reduction in the crop's photosynthetically active biomass which can be captured with NDVI (Tucker, 1979).

The inclusion of NDVI in our model improves the price predictions in a statistically significant way, although the magnitude of the effect is rather small: the with-NDVI model reduces the average forecast error between 56 and 67 percent of the time, relative to a model that excludes NDVI data. ${ }^{2}$ We think that this is due to the fact that NDVI measures apply to all vegetation in a region, not just crop growth. Linking NDVI with information about planted area would likely increase the predictive power of NDVI, but unfortunately high resolution, comprehensive information about the annual variation of area in cultivation since 1995 is not available on the local level in West Africa.

Our model is meant to serve as a forecasting tool that can be used by parties - such as aid organizations or countries - that are interested in anticipating future prices, perhaps for the purpose of planning interventions. While it is true that both high and low prices have generated policy debates about the threats of each to developing countries

${ }^{2}$ The error in the full sample model is lower with NDVI 56 percent of the time in the Niger model, 59 percent of the time in the Burkina Faso model, and 67 percent of the time in the Niger model. 
(Swinnen, 2011), unusually high prices will tend to be associated with low immediate access to food for consumers. The concern with persistently low prices is that net sellers of food are unable to generate enough income to afford things other than food, while temporarily low prices (seasonal price lows, for instance) might presage future inability for farmers to purchase food (if farmers are unable to store their own production, they may use sales to finance food purchases when their stock runs out). Since our model is constructed to predict food prices up to four months in the future, the main utility of the model will be monitoring for potential short-term changes - extremely high local prices, say - rather than longer-term concerns about development and the ability of agricultural producers to climb out of poverty.

The model that we generate is unique - no other published results create a quantitative and objective millet forecasting model for this area of the world in which much of the population is engaged in subsistence agriculture. Much of the existing architecture for food security prediction in Africa uses more labor-intensive models, including qualitative analysis. For example, the Famine Early Warning Systems Network, or FEWSNET, makes and publishes publicly available forecasts for food security levels in more than 35 countries in the world, including all of the Sahel. The forecasts that FEWSNET publishes are, however, based on scenario development and food security forecasts are predominantly qualitative in nature (regular price forecasts are not provided except as an input to food security forecasts). We believe that quantitative price forecasts, which come with the ability to describe uncertainty precisely, could be a complement to the forecasting system constructed by FEWSNET. Not only could 
forecasted prices be used as inputs to food security forecasts, but their public display could encourage forecast improvement, as more researchers critique the methods we describe here. $^{3}$

\section{Food markets in West Africa}

In the following we will briefly describe agricultural conditions in West Africa and introduce the main drivers for local millet prices that we use in our analysis.

\subsection{Political and Infrastructure Conditions}

Mali, Burkina Faso and Niger are part of the West African Economic and Monetary Union, which was established in 1994 among countries using the CFA Franc; each of the countries obtained independence from France in 1960. Burkina Faso established its current constitution in 1991, and while Mali and Niger also established constitutions in 1991, Niger has seen several revolutions since, and Mali temporarily suspended its constitution in 2012. Niger experienced military rule after 1991, and did not establish democratic governance until 1999 (democratic rule continued until 2010, after the sample period used in our model). Recent years have brought significant political crises in

\footnotetext{
${ }^{3}$ The Food and Agriculture Organization has recently begun publishing price forecasts for major crops as part of its Agricultural Market Information System; only world-level price predictions are provided. The International Food Policy Research Institute uses the IMPACT tool to predict excessive volatility in food prices for major internationallytraded commodities. Neither system predicts local prices of millet.
} 
neighboring countries of the Central African Republic, Chad and in Libya to the north, and in the northern regions of Mali and Niger has increased the stress on public finances, risk perception by investors and has reduced overall growth (IMF, 2013). During the early 2000s, however, the political situation was far more stable.

Mali, Niger and Burkina Faso have weak financial sectors, a need to improve the functioning of institutions, governance, and physical infrastructure (WorldBank, 2014). Although each of the countries is poor with weak overall institutions, economic conditions are not identical. Over the 1980-2012 period (as well as over the 1995-2006 period of our sample) Burkina Faso has the highest average growth of the three, as well as the lowest standard deviation of GDP growth (4.9\% annual growth over the 19802012 period, and nearly 6.5\% growth over the 1995-2006 period). Mali has a lower growth rate (3.8\% and $4.9 \%$ over the two periods) and a higher standard deviation of the growth rate. Niger experienced both the lowest average annual economic growth (2.6\% and 3.7\%) and the highest variability. Burkina Faso unsurprisingly has better infrastructure as well, with a significantly higher road density than Mali or Niger, perhaps aiding the movement of millet and other foodstuffs between markets and thus allowing for more efficient price transformation across space. ${ }^{4}$

Each of the countries has been a recipient of a substantial inflow of food aid before, during, and after the period of our study. The three panels of figure 1 show total food aid

${ }^{4}$ Source: World Bank WDI data. 
to Burkina Faso, Mali, and Niger. Total food aid over the period is highest in Niger, next-highest in Burkina Faso, and lowest in Mali. This relationship remains the same if food aid is measured as a proportion of domestic cereals production or on a per-capita basis. Although there is substantial variation in food aid over time in each country, it appears that the price of food in Niger is likely to be most influenced by external aid, while the price of food in Mali is likely to be least influenced. ${ }^{5}$

\subsection{Agricultural conditions}

Technological change has transformed agriculture in the US, Europe and large parts of Asia and South America, but it has largely bypassed West Africa. In this region, most farms are small, primarily cultivated with hand tools, planted with seeds with a low yield potential, using little or no chemical or organic fertilizer. The climate is arid or semiarid, and there is inadequate infrastructure to provide water for irrigation. Consequently,

${ }^{5}$ While the presence of a significant amount of food aid is likely to impact local food prices, we do not include aid figures in our forecasting model. We do not include aid because of our focus on selecting data that is available at the time a forecast needs to be made - that is, data on food aid are typically not available for more than a year (2012 data will be released in 2014, for instance). Clearly, it is current aid, not lagged aid that would affect current food prices. If, however, aid were autocorrelated, then lagged aid could be used as a proxy for current aid. We tested country-level aid data from the World Food Program for Burkina Faso, Mali, and Niger and found little autocorrelation. The Portmanteau (Q) test for white noise fails to reject the null hypothesis of white noise for all lags of aid on a series of annual data from 1988 to 2012. Full results available from the authors upon request. 
most small farms are only able to attain yields which are less than one seventh of those regularly achieved in industrialized systems (Breman, 2003; Taylor et al., 2002).

Burkina Faso, Mali and Niger, are all landlocked countries in the West African Sahel. Niger has significantly more arable land than Burkina Faso or Niger $(152,000$ square kilometers compared to about 58,000 and 68,000, respectively), though Mali has significantly more freshwater resources than the other countries, and devotes a significant portion of its freshwater withdrawals to agriculture (World Fact Book 2014; Economic Research Service 2013). Despite high rainfall variability, rain-fed agriculture remains one of the main sources of income for the population of all countries, however. Table 1 provides basic descriptive statistics for the three countries. According to a typology of food security by Yu et al. (2009), all of these West African countries are "trade insecure," meaning that they are net food importers and that they spend more than $10 \%$ of export revenue on food imports. Furthermore, their climate is considered to be unfavorable to agriculture and they are classified as countries with low food production, most of which is consumed locally. Because of the difficult growing conditions and the risk inherent in agricultural activity, most farmers have diversified their income sources by raising livestock and working in wage labor markets (Abdulai and CroleRees, 2001), some to the extent of becoming net purchasers of food (Brown et al., 2009a; Bryceson, 2002).

Although each country is food insecure, they do regularly produce $70 \%$ or more of their cereal needs (Kelly et al., 2008). Domestic coarse grains make up a significant portion of total food consumption, especially for the rural poor (Breman, 2003). The 
most widely available grain, and the grain most frequently purchased when farmers’ own production is exhausted, is millet (Jayne et. al. 1996 and Brown 2008). We focus exclusively on millet in our analysis. Millet can be grown even in semi-arid zones where most other crops require irrigation. Planting time varies between April and July depending on local growing conditions, and the seeds take about 60-70 days to mature (Baker, 2003). In Burkina Faso and Mali, most areas harvest in October, whereas the predominant harvest time in Niger is in September (Terpend 2006).

\section{Millet price forecasting model}

Our objective is to project millet price variations four months into the future. We focus on a four-months projection because 1) knowing that rising food prices will persist or worsen over a period of several months can significantly improve the response of humanitarian agencies (Buchanan-Smith and Davies, 1995); 2) NDVI information can be estimated with a high degree of accuracy four months ahead using observed humidity and rainfall (Funk and Brown, 2006); and 3) being able to identify high prices in some markets but not in those around it can help aid organizations target areas where food availability might be low (Brown et al. 2013).

\subsection{Observed millet price determinants}

There are a series of millet price drivers for which there exists no data on the market- or sometimes even the country-level, the most important of which are the harvested amount and the location and extent of the area harvested. We remove the time- 
invariant part of the unobserved heterogeneity in local millet prices by including marketlevel fixed effects but are unable to control for unobserved variables that vary over time. In this subsection we present the observable variables that we have used in the model because of their theoretical relationship to local millet prices.

\subsubsection{Global rice and wheat prices}

Although millet is a West African food staple in the sense that it is the most cultivated and most consumed cereal, there is practically no global market for it. The vast majority of millet consumed in West Africa is also produced there, with very little imports and even less exports recorded by the FAO. Although regional trade does occur, it is not usually observed by authorities and is not captured by trade statistics (Allen, 1998). Because of this, millet is considered to be an imperfectly traded commodity (Dorosh and Subran, 2009). The three countries in our study are linked to international food markets via other grains that serve as caloric substitutes for millet and which we therefore expect to be correlated with the millet price. We do not expect this correlation to be perfect, as market integration seems to be incomplete (Brown et al., 2009b).

Cereal imports combined for 14.24 million tons in the period between 1982 and 2006, compared with 0.84 million tons of exports. ${ }^{6}$ An additional 3 million tons of

\footnotetext{
${ }^{6}$ FAO trade statistics, http://faostat.fao.org/site/535/default.aspx\#ancor, last accessed in October 2013.
} We chose this time frame in order to match it with our local millet price dataset. 
cereals entered the region in the form of food aid over the same time frame. Millet constitutes only a minor fraction of this trade. As can be seen in Figure 2, the main import cereals are rice and wheat, and to a lesser extent corn. We include global wheat and rice prices as explanatory variables in our model, and allow for their effect to differ depending on the rice/millet and wheat/millet price differential, adjusted for import costs and caloric content.

Although there is little international trade in millet, there exists domestic trade between local markets and to some extent also regional trade across neighboring countries. Traders buy millet from farmers in surplus areas and sell it to city markets for purchase by consumers as well as other traders that transport millet to rural areas with a millet shortage (Terpend, 2006). The spatial correlation between local millet prices mentioned above is consistent with such regional trade, although it could also be due to spatial correlation of millet price determinants other than transportation costs. Imports from overseas arrive in the capital and port cities and are distributed to rural markets via the same distribution channels. We therefore weigh the effect of wheat and rice prices on the price of millet in a particular market by this market's inverse distance (in $100 \mathrm{~km}$ ) to the capital city.

\subsubsection{Inter-annual variation of production: NDVI}

Figure 3 shows average millet prices by country between 1995 and 2006. Prices vary a lot during this period, both within and across years. Because of imperfect integration into international markets, important millet price drivers include regional and 
local output variations. For example, weather-related harvest reductions cause significant increases in local food prices (Brown et al., 2006). In contrast, globally traded commodities are largely unaffected by local growing conditions because prices are determined by world output.

We proxy for crop output by means of the AVHRR normalized differenced vegetation index (NDVI) (Rasmussen, 1997; Rasmussen, 1998b), which is an index of "greenness" and measures the fraction of the incoming visible light used in plant photosynthesis on a scale between 0 (no absorption) and 1 (complete absorption). To the extent that cropped area is static over time, variation in NDVI will reflect variation in millet supply due to moisture conditions (Kastensa et al. 2005, Reynolds et al. 2000, and Rasmussen 1997, for example). Variation in NDVI over time and across space that instead reflects variation in non-crop vegetation will tend to attenuate the significance of NDVI in our model. If we had local data detailing planted areas, we could use the product of area planted and NDVI to proxy for output (Husak et al. 2008). Information about harvested area is published by the FAO, but there are concerns about the accuracy of this information, and more importantly, it is published only with a delay of 1-2 years along with the harvest amounts, making them useless for real-time prediction. Since our goal is to create a short-term forecasting model that is useful in providing timely information to policymakers, we opt not to use information on harvested area.

NDVI data have been used extensively in the Sahel to detect variations in vegetation growing conditions, and have been shown by a number of authors to be correlated to both net primary production (NPP), crop yields (Fuller, 1998; Maselli et al., 1993; Maselli et 
al., 2000; Prince, 1991; Rasmussen, 1992; Tucker, 1985), and precipitation (Nicholson, 1994). Because the relevant parts of the remote sensing literature are technical and results are not well-known by the broader community of food policy researchers, we provide an analysis of the NDVI-to-output connection for our particular application, using the best available data. At the country-level, the link between NDVI and output is well established, as is reflected by the widespread continued use of NDVI anomalies to indicate food production declines (Brown and Brickley, 2012; Verdin et al., 2005)..

There are many ways in which NDVI can be specified to enter a production model. Examples in the literature include the summation of NDVI over the growing season (e.g. Jiang et al., (2004)Rasmussen, (1998a), the maximum NDVI over the growing season (Fuller, (1998), or NDVI in the month prior to harvest (Basnyat et al., (2004). In our data, the NDVI/output correlation is highest when using the maximum NDVI during the millet growing season, defined as May-September (Holben, 1986), and we use this measure for the remainder of the paper. Figure 4 shows the relationship between NDVI for the cereal production zone during the millet growing season and annual output for each of the three countries, and there is clearly a positive correlation.

Lastly, we capture output changes over time due to technological change and population growth by introducing a time trend.

\subsubsection{Intra-annual price fluctuations}

Unlike cereal prices in industrialized countries, prices for non-traded local food staples in West Africa such as millet and sorghum exhibit strong intra-annual variation. 
Figure 4 shows average deflated monthly millet prices by country. The average relative intra-annual variation ranges from $25 \%$ of post-harvest prices in Burkina Faso to more than $50 \%$ in Niger. We control for the cyclical behavior of prices by introducing monthly dummy variables, as well as interactions between monthly dummies and NDVI during the growing season.

The reasons for this variability are twofold: First and foremost, there is a widespread lack of storage facilities (Dembele and Staatz, 1999). Because storage is not available or is costly, small farmers sell more than their surplus (defined by total output minus annual consumption) on the market after harvest and buy some grain back later in the year, often at higher prices (Jones and Lowenberg-Deboer 2011 and Shepherd 2012). Because of the simultaneous influx of grain, prices drop to their base levels after harvest. As producers draw down their stocks, supply on the market decreases whereas consumer demand remains unchanged, leading to a gradual increase of millet prices during spring. During the "hungry season" in summer, many farmers become millet buyers because their own stocks are depleted, further boosting prices (Cekan, 1992). Presumably, it is during this period that international cereal imports and aid shipments enter the region, provided that prices surpass import parity. Annual prices peak just before harvest, the time of which differs across climate zones. Prices in Burkina Faso and in Mali are highest in August, whereas the average price peak in Niger occurs in July.

The second reason for the observed intra-annual price pattern is asymmetric integration into global markets in general and the lack of a sufficiently liquid international market for millet in particular, as discussed above (Cornia et al. 2012). 
Perfect integration into an international millet market would act as a partial substitute for storage in the sense that farmers could export after harvest instead of driving down local prices and import when their own stocks are low during summer.

\subsubsection{Income}

A number of economic indicators are available on an annual level by country. Because we are focusing on data that is available when predicting prices in the next soudure season, however, and these economic data are frequently not available until the end of the following year, we have to rely on 24-month lags. For example, when predicting the price in June 2014, the latest available information for economic indicators are from 2012). For most economic indicator variables it is not clear why two-year lags should predict anything about this year's prices. ${ }^{7}$ To the extent that income is autocorrelated over time, lagged income may be a predictor for current millet demand. We therefore included lagged income (adjusted GNI/capita) in all of our regressions.

\subsection{Econometric model}

For each country, we estimate a reduced-form fixed effects panel model, where $i \in(1, \ldots, N)$ and $t \in(1, \ldots, T)$ index the market and time period, respectively:

\footnotetext{
${ }^{7}$ See footnote 5 , for example, for an explanation of why we decided not to use data on aid in our forecasting
} model. 


$$
\begin{aligned}
& y_{i t}=\alpha_{0 i}+\alpha_{1} t+\alpha_{2} M_{t}+\frac{B(L) G_{t}}{D_{i, c a p}}+\gamma_{1} V_{i t}^{\text {local }}+\gamma_{2} V_{t}^{\text {crop }}+\gamma_{3}\left(V_{t}^{\text {crop }} \cdot M_{t}\right)+ \\
& \delta I_{t-24}+\epsilon_{i t}(1)
\end{aligned}
$$

The dependent variable $y_{i t}$ refers to the natural logarithm of millet price in market $i$ at month $t$. We decided in favor of logs based on a test originally derived by Sargan (1964) and implemented by Godfrey and Wickens (1981). We include monthly dummies in the (1 x 12) vector $M_{t}$ to account for the seasonal nature of millet prices, as well as a linear trend. The lag polynomial $B(L) \equiv \sum_{q=h}^{Q} \beta_{q} L^{q}$ of order $Q$ is associated with the logarithm of world prices for grain represented by the vector $G_{t}$, which contains future prices of various maturity for wheat, and the one-month future price for rice. We convert all prices to constant $2000 \mathrm{CFA}$, using the appropriate exchange rate and country-level consumer price indices. Because we are interested in predicting prices $h$ periods into the future, we restrict all price lags to order $h$ or greater. We divide this polynomial by the Euclidean distance between market $i$ and the capital city $D_{i, \text { cap }}$ in units of $100 \mathrm{~km} .{ }^{8}$ $V_{i t}^{\text {local }}$ refers to the maximum NDVI value during the preceding growing season (May-September) in a 5x5 km area centered around market $i$ and is a proxy for local

${ }^{8}$ For the capital cities themselves, we define $D_{i, c a p}=0.01$. Using inverse distance as a weight is admittedly ad hoc. We also tried weighting by inverse square distance, and using rice rather than wheat prices, but the results were qualitatively similar. 
millet production, whereas $V_{t}^{\text {crop }}$ refers to the corresponding NDVI value in the crop production zone and is a measure of country-wide millet production. Since NDVI captures vegetation anomalies, the link to millet is limited to the choice of the growing season over which the maximum NDVI is computed. We further included an interaction term between country-level NDVI and monthly dummies to account for the possibility that the amount of millet harvest affects the price differently across the year. $I_{t-24}$ represents the most recently available (annual) income data, as described above.

The effect $u_{i} \sim N\left(0, \sigma_{u}^{2}\right)$ captures unobserved time-invariant heterogeneity across markets, such as the quality of the surrounding agricultural land, connectedness to other markets and local institutions like marketing boards. These unobserved characteristics could well be correlated with local NDVI or the distance to the capital city, in which case estimating the regression by generalized least squares (GLS) using random effects specification (assigning a constant error component to each market in addition to the idiosyncratic error) could lead to severely biased coefficient estimates. Finally, $\varepsilon_{i t}$ is a normally distributed, but potentially heteroskedastic error term with $E\left[\varepsilon_{i t}\right]=0$, $E\left[\varepsilon_{i t}^{2}\right]=\sigma_{\varepsilon}^{2}, E\left[\varepsilon_{i t} \cdot \varepsilon_{i s}\right]=0$ for $t \neq s$ and $E\left[\varepsilon_{i t} \cdot \varepsilon_{j t}\right]=0$ for $i \neq j$. We estimate the parameters $\left(\alpha_{0}, \alpha_{1}, \alpha_{2}, \beta_{0}, \ldots, \beta_{q}, \gamma_{1}, \gamma_{2}, \gamma_{3}, \delta\right)$ by maximum likelihood.

Even though the forecast precision could be increased by including lagged dependent variables as regressors, we decided against this for two reasons: First, this would significantly reduce our sample because the millet price information has many gaps. All observations that do not have price information in the previous month would be 
lost. Second, our specification allows for price forecasts based on information that is readily available anywhere in the world, because we only rely on global cereal prices and NDVI information.

In order to assess the predictive power of our model relative to alternative models, we compare the predictions with those based on specifications where we regress the model jointly for all three countries, where we include regional rather than market-level fixed effects, and where we aggregate the data on a regional level. Last, to check for the possibility of over-fitting we estimate the model based on $80 \%$ of the data and compare the prediction errors with those associated with out-of-sample predictions.

\subsection{Price predictions}

Millet price predictions $h$ periods into the future are given by

$$
\begin{aligned}
\hat{y}_{i, t+h}=\hat{\alpha}_{0}+ & \hat{\alpha}_{1}(t+h)+\hat{\alpha}_{2} M_{t+h}+\sum_{q=0}^{Q-h} \frac{\hat{\beta}_{q} L^{q} G_{t}}{D_{i, c a p}}+\hat{\gamma}_{1} V_{i, t+h}^{\text {local }}+\hat{\gamma}_{2} V_{t+h}^{\text {crop }} \\
& +\gamma_{t}\left(V_{t+h}^{\text {crop }} \cdot M_{t+h}\right)+\delta I_{t-24}+\hat{u}_{i}
\end{aligned}
$$

Since NDVI is not predicted, but only measured and reported after the fact, we exclude the $h=4$ months after the harvest from our predictions. From a food aid perspective, price forecasts for this time of the year is less relevant than for the soudure season when prices are high.

After estimating (1) we compute the 4-period predictions $\hat{y}_{i t+4}$ and compare them with actual prices $y_{i t+4}$. To obtain a measure of fit, we compute the mean absolute 
prediction error (MAPE) relative to the actually observed price, which involves exponentiating the prices and predictions as we estimate the model in logs: ${ }^{9}$

$$
Z=\frac{1}{N \cdot T} \sum_{i=1}^{N} \sum_{t=4}^{T} \frac{\left|e^{y_{t i}}-e^{\hat{y}_{t t}}\right|}{e^{y_{t i}}}
$$

To assess the importance of including NDVI into the price forecast, we re-estimate (1) while setting $\gamma_{1}=\gamma_{2}=\gamma_{3}=0$, compute predictions $\hat{y}_{t}^{\text {noveg }}$ according to (2) and $Z^{\text {noveg }}$ according to (3). If NDVI is useful in predicting local millet prices it has to be the case that the average prediction error without NDVI exceeds the average prediction error of the model that includes NDVI information, such that $Z^{\text {noveg }}>Z$. . Lastly, we compare the MAPE from our preferred model to that from alternative model specifications.

\subsection{Data}

The average monthly millet prices were from each country’s cereals market information system (SIM) based at each country's cereal marketing boards. The prices

\footnotetext{
${ }^{9}$ We also report MAPE-R as well, since the MAPE figures can be misleading when there are large outliers, as there are in our price series predictions. See http://www.census.gov/population/www/documentation/twps0057/twps0057.html for details on calculation of MAPER.
} 
were provided to USAID's FEWS NET at the time of acquisition and have been maintained at the Washington DC office over multiple phases of the FEWS NET program for ongoing food security analysis (Brown, 2008; Chopak, 1999; May, 1991). Because the data are used for food security analysis, they are retail prices at the market measured in single kilogram purchases, the most common quantity sold at the market. The data have been kept in the local currency CFA ${ }^{10}$. The original data covers the time span 1982 through December 2006, but due to devaluation of the CFA in 1994 we focus on prices starting in 1995 . We deflated the millet price data with a national annual consumer price index (CPI), interpolated across months. Average millet prices for each country from January 1995 to December 2006 are presented in figure 4, along with the global wheat price. During the analysis we had to drop 210 markets due to incomplete data or unverifiable location. The excluded markets were throughout the region, but a disproportionate number were located in Burkina Faso. Excluding data prior to 1995 further reduced the sample by 73 markets. Of the remaining 162 markets included in the analysis, 26 are located in Burkina Faso, 86 in Mali and 50 in Niger.

Using geographic location we are able to match prices with Normalized Difference Vegetation Index (NDVI) data, which also exists at the monthly level. NDVI data were obtained from the NOAA Advanced Very High Resolution Radiometer (AVHRR)

10 The CFA (Franc de la Communauté Financière d'Afrique) is fixed for all three countries at the same exchange rate with the French franc before 2002, and with the Euro after that. 
archive, which has 8 x $8 \mathrm{~km}$ spatial and monthly temporal resolutions. The data were processed by the Global Inventory Monitoring and Mapping Systems (GIMMS) group at the NASA Goddard Space Flight Center (Tucker et al., 2005). The AVHRR sensor has appropriate spatial, spectral and temporal resolutions to monitor the entire Earth, hence it is adequate to cover all West Africa (Justice et al., 1991; Townshend, 1994). For our local measure of NDVI we computed the mean of a five by five-pixel box ( $40 \mathrm{x} 40 \mathrm{~km}$ ) centered on each market from monthly maximum value NDVI composites (Holben, 1986). The country-level NDVI values were averaged from all cropped pixels (Monfreda et al 2008) in each country for each month using the GIMMS NDVI data, creating a time series of the average productivity for the entire country for each time period.

We use wheat and rice futures from the Chicago Board of Trade, accessed via Thomson Reuters Datastream. We converted all prices to CFA $/ \mathrm{kg}$ deflated to 2000 prices. Summary statistics of our data are presented in Table 2.

\section{Results}

To test for stationarity of the data, we employed a panel unit root test developed by Maddala and Wu (1999) and refined by Choi (2001) (also known as the ADF-Fisher 
test ${ }^{11}$, which involves carrying out a unit root test for all individual groups and using the p-values from these tests to build an aggregate measure of stationarity. We were able to reject the null of all markets being nonstationary at $\mathrm{p}<0.001$, irrespective of the lag order chosen for the ADF tests. We therefore proceed under the assumption of stationarity. ${ }^{12}$

Based on data availability and the Akaike Information Criterion, we included lags 4, 5 and 12 each for wheat and rice monthly futures, as well as lag 4 of two-, three- and four-month futures for wheat (we do not have access to these futures for rice). The latter corresponds to the predicted time horizon, whereas all other prices refer to prior months. Table 3 presents the results from estimating (1) by country, with some of the parameter estimates suppressed for ease of exposition. ${ }^{13}$ The "within" variation (i.e. the variation for a particular market, conditional on the fixed effect) is much higher than overall variation, underscoring the importance of unobserved heterogeity and thus of the fixed effects. The set of monthly dummies is highly significant for all countries, confirming the strongly cyclical pattern of millet prices shown in Figs. 2 and 4. There is a small but significant positive time trend for Niger, but none for Burkina Faso and Mali. Global

${ }^{11}$ There exists a range of panel unit root tests, but the ADF-Fisher test is the only one that does not require the panel to be balanced.

${ }^{12}$ Since we are not interested in individual parameters but a price prediction, the question of stationarity loses much of its urgency.

${ }^{13} \mathrm{~A}$ full set of results is available from the authors upon request. 
cereal prices are jointly significant, although the precise relationship is not straightforward to assess because of the lag structure.

The variables involving NDVI are jointly significant, but the sign varies across countries. This is the case even when taking into account the interaction terms with the monthly dummies (not shown in the table). However, since we have a lot of similar price information in the model, and some of the involved price series may not be stationary, the individual coefficient estimates may be biased. Therefore we do not focus on the individual coefficients, but rather on the predictive power of the model with NDVI information, relative to that without NDVI, as our goal is to provide the best-performing short-term forecasting model. Table 4 shows the mean average prediction error. Including NDVI in the model reduces the forecast error in all cases, but the size of the effect varies significantly depending on whether the full sample is considered, and whether the predictions are in-sample or out-of-sample (see Tables 4 and 5 for comparisons).

We checked for the robustness of our results by computing out-of-sample predictions using the base model and out-of-sample predictions using an iterative model. To do the former we randomly assigned $80 \%$ of our data to estimate the coefficients of the included determinants, reserving $20 \%$ for out-of sample comparisons. The coefficient estimates and the resulting associated $Z$ and $Z^{\text {noveg }}$ measures were very similar. Likewise, the dispersion of the forecast errors in and out of sample is similar as shown in Figure 5, indicating that over-fitting (which is potentially an issue considering the reduced-form nature of our approach) should not be a problem. To compute out-of- 
sample predictions from the iterative model, we ran our model on a training dataset separately for each country, then used the coefficients from this initial dataset to predict four periods ahead $(\mathrm{T}+4)$. We then incorporated period $\mathrm{T}+1$ into the training dataset, recomputed the coefficients, and predicted period $\mathrm{T}+5$ price. The results of this exercise are displayed in Table 5.

We further tested whether all fixed effects are equal, which would be the implicit assumption of a regression by OLS, but we had to reject this hypothesis in favor of individual intercepts. Accordingly, the fraction of the total error variance $\left(\sigma_{u}^{2} /\left(\sigma_{\varepsilon}^{2}+\sigma_{u}^{2}\right)\right)$ due to the variance of the fixed effects is high.

Next, we tested whether it would be appropriate to combine all three countries into one large panel dataset and estimate a joint model. This is equivalent to assuming that the impact of the included regressors on millet prices is the same across countries, while controlling for market-specific heterogeneity using the fixed effects. Using LR tests and country interaction dummies on various subsets of the included variables we arrived at a strong rejection of this hypothesis. This is probably due to the fact that in spite of being located in the Sahel, the actual climates and soil qualities of these countries are quite different (Yu et al., 2009). Also, the countries differ in size and income levels (Table 1).

Given the high variation of millet prices across markets, we re-estimated the model after aggregating the data to the level of regions defined as "livelihood zones" by FEWSnet. The lower panel in Table 4 shows the MAPEs for the regional model, estimated separately by country as well as jointly. The MAPE from the regional model, when estimated by country, is generally smaller than that from market-level regression. 
This suggests that if the focus is the region rather than an individual market, using the regionally aggregated model yields more precise estimates.

Figures 6-8 show average observed market prices by country, along with average predictions from the market-level as well as the regional model. As discussed above, these predictions are based on information available anywhere in the world, which comes at a cost of accuracy but has the important advantage that it can be implemented quickly for any market, even in times when no local millet price information is available.

\section{Conclusions}

In this article we construct a millet price prediction model for 162 small, informal markets located in Burkina Faso, Mali and Niger. We control for intra-annual price variation due to imperfect storage and asymmetric integration into world markets, prices

of imported cereals and the expected millet harvest on the country level as well as on the local level as proxied by NDVI. We exclude lagged millet prices as explanatory variables, which lowers the forecasting precision but has the important advantage that our model allows to compute local millet price predictions independent of local information.

We find that including maximum NDVI during the preceding growing season reduces the forecast error by 1-2 percentage points compared to a model that excludes NDVI information. However, the explanatory power of NDVI is relatively low, and especially the large price peaks are not well explained by our model. We believe that this is due to two reasons: First, NDVI is an imperfect measure for millet supply. It 
measures all types of photosynthetic activity, including that of trees and weeds, and it is a proxy for yield rather than output. A much better proxy for millet supply would be obtained by multiplying NDVI measured specifically for areas under cultivation with the respective area. Unfortunately, information about the size and location of the area under cultivation is not available, at least not in a timely fashion to allow for price forecasts. NDVI also cannot capture non-weather related production deficits, such as inadequate planting for food needs, damage due to wind, and other non-biophysical problems. This results in a measurement error of true cereal supply, and it is well known that measurement errors lead to a downward bias of the coefficient estimates.

Second, there are likely reasons other than millet supply that affect prices, including demand shocks, political events, and non-weather related production deficits for which we are not able to control.

With this research, we have developed a price prediction model that can be of use in early warning of food insecurity as well as in planning and implementing an appropriate response, especially in combination with additional information about cropped areas. Because most food security crises in West Africa are caused by an inability to purchase food instead of an overall food availability problem, monitoring and forecasting food prices should contribute to improved response. The global price fluctuations in 2008 have shown that even West Africa, one of the most isolated regions of the world, can be negatively affected by increases in global commodity prices (Brown et al., 2009b). Implementing a local price projection model for these food insecure regions could reduce 
their exposure and vulnerability to such variations by providing the possibility for appropriate policy response. 


\section{Tables}

Table 1: Background Information for Burkina Faso, Mali and Niger

\begin{tabular}{|c|c|c|c|}
\hline & Burkina Faso & Mali & Niger \\
\hline Population in 2006 (million) & 15.7 & 12.7 & 15.3 \\
\hline Surface area $(1,000$ km²) & 274 & 1,240 & 1,267 \\
\hline Arable land (\% of total) & 17.60 & 3.76 & 11.43 \\
\hline Permanent crop land (\%) & 0.22 & 0.03 & 0.01 \\
\hline GDP, PPP (million 2008 US\$) & 17,820 & 14,590 & 10,040 \\
\hline GDP per capita (2008 US\$) & 1,132 & 1,152 & 656 \\
\hline Currency & CFA & CFA & CFA \\
\hline Agriculture (\% of GDP) & 29 & 45 & 39 \\
\hline Agricultural workforce (\%) & 90 & 80 & 90 \\
\hline $\begin{array}{l}\text { International food assistance } \\
\text { Average 1995-2006 (tons) }\end{array}$ & 37,671 & 21,043 & 50,934 \\
\hline $\begin{array}{l}\text { International food assistance } \\
\text { Average 1995-2006 (tons } \\
\text { per capita) }\end{array}$ & 0.0032 & 0.0020 & 0.0044 \\
\hline Capital City & Ouagadougou & Bamako & Niamey \\
\hline
\end{tabular}


Table 2: Summary statistic of prices and NDVI information, 1995-2006

\begin{tabular}{|c|c|c|c|}
\hline & Burkina Faso & Mali & Niger \\
\hline Millet pr & 26 & 86 & 50 \\
\hline \multicolumn{4}{|c|}{ Millet price (2000 CFA/kg) } \\
\hline mean & 129.49 & 126.46 & 136.89 \\
\hline st.dev. & 33.55 & 38.35 & 47.00 \\
\hline \multicolumn{4}{|c|}{ Internat. wheat price (2000 CFA/kg) } \\
\hline mean & 72.67 & 71.04 & 71.49 \\
\hline st.dev. & 14.43 & 13.04 & 14.60 \\
\hline \multicolumn{4}{|c|}{ Internat. rice price (2000 CFA/kg) } \\
\hline mean & 48.43 & 48.43 & 47.39 \\
\hline st.dev. & 13.75 & 13.75 & 13.17 \\
\hline \multicolumn{4}{|c|}{ Distance to capital city (km) } \\
\hline mean & 293.12 & 332.07 & 466.68 \\
\hline st.dev. & 194.35 & 293.30 & 301.50 \\
\hline \multicolumn{4}{|c|}{$\begin{array}{l}\text { Local NDVI (max. in growing } \\
\text { season) }\end{array}$} \\
\hline mean & 0.534 & 0.460 & 0.257 \\
\hline st.dev. & 0.079 & 0.175 & 0.081 \\
\hline \multicolumn{4}{|c|}{$\begin{array}{l}\text { Cropland NDVI (max. in growing } \\
\text { season) }\end{array}$} \\
\hline mean & 0.514 & 0.469 & 0.262 \\
\hline st.dev. & 0.025 & 0.020 & 0.023 \\
\hline
\end{tabular}


Table 3: Estimation results

\begin{tabular}{|c|c|c|c|c|c|c|c|c|c|c|c|c|}
\hline & \multicolumn{4}{|c|}{$\begin{array}{l}\text { Burkina Faso } \\
\text { (1,362 obs. from } 52 \text { markets) }\end{array}$} & \multicolumn{4}{|c|}{$\begin{array}{l}\text { Mali } \\
(4,424 \text { obs. from } 86 \text { markets })\end{array}$} & \multicolumn{4}{|c|}{$\begin{array}{l}\text { Niger } \\
(5,019 \text { obs. from } 50 \text { markets })\end{array}$} \\
\hline & Coeff & $\mathrm{t}$ & Coeff & $\mathrm{t}$ & Coeff & $\mathrm{t}$ & Coeff & $\mathrm{t}$ & Coeff & $\mathrm{t}$ & Coeff & $\mathrm{t}$ \\
\hline L4.wheat_4mf & -1.2860 & -2.98 & 1.3694 & 4.46 & -1.3718 & -4.83 & -0.7247 & -3.88 & 1.8555 & 7.01 & 1.2753 & 9.60 \\
\hline L4.wheat_3mf & -0.5781 & -2.51 & -0.4279 & -1.83 & 0.1132 & 1.11 & -0.2828 & -2.65 & 1.1327 & 8.29 & 0.4502 & 4.84 \\
\hline L4.wheat_2mf & 1.7293 & 4.19 & -1.3321 & -5.56 & 0.5072 & 2.39 & -0.0993 & -0.76 & -3.4746 & -15.80 & -2.0245 & -14.80 \\
\hline L4.wheat_1mf & 0.2836 & 2.67 & 0.3815 & 4.26 & 0.6524 & 6.78 & 0.8684 & 6.67 & 0.3826 & 11.70 & 0.4270 & 15.60 \\
\hline L5.wheat_1mf & -0.0655 & -0.81 & 0.1728 & 2.09 & 0.2415 & 6.20 & 0.4122 & 8.37 & 0.3428 & 11.70 & 0.3973 & 15.90 \\
\hline L12.wheat_1mf & 0.4010 & 7.94 & 0.3952 & 10.30 & 0.3735 & 8.90 & 0.3327 & 10.10 & 0.1104 & 4.33 & 0.3928 & 14.90 \\
\hline L4.wheat_1mf & 0.3080 & 2.59 & 0.0169 & 0.15 & -0.0188 & -0.30 & -0.0424 & -1.00 & -0.1590 & -8.45 & -0.0798 & -4.00 \\
\hline L5.wheat_1mf & 0.6257 & 5.93 & 0.0894 & 1.26 & 0.3393 & 5.21 & 0.1998 & 5.07 & 0.0848 & 4.33 & 0.1239 & 4.95 \\
\hline L12.wheat_1mf & 0.1547 & 3.96 & 0.1713 & 4.82 & 0.0855 & 4.19 & 0.1562 & 6.48 & 0.6282 & 31.60 & 0.5358 & 28.10 \\
\hline L24.income & 0.0081 & 1.00 & 0.0279 & 3.16 & -0.0061 & -1.85 & -0.0038 & -1.08 & 0.0189 & 27.90 & 0.0103 & 20.50 \\
\hline $\begin{array}{l}\text { Month } \\
\text { dummies }\end{array}$ & included & & included & & included & & included & & included & & Included & \\
\hline Trend & -0.0034 & -0.72 & -0.0112 & -1.95 & 0.0050 & 5.10 & 0.0044 & 4.55 & 0.0052 & 27.30 & 0.0067 & 29.00 \\
\hline $\mathrm{NDVI}^{\mathrm{crop}}$ & 2.2734 & 4.47 & & & 2.1963 & 5.27 & & & -4.4459 & -14.00 & & \\
\hline NDVI local & 0.0880 & 0.27 & & & -0.6783 & -2.81 & & & -0.9651 & -6.52 & & \\
\hline M x NDVI ${ }^{\text {crop }}$ & included & & & & included & & & & included & & & \\
\hline Constant & -2.2595 & -3.63 & 0.4349 & 0.73 & 0.3487 & 0.65 & 1.2418 & 2.84 & 0.4245 & 2.26 & -2.3477 & -11.10 \\
\hline $\mathrm{LL}$ & 740.4 & & 649.7 & & 995.0 & & 640.8 & & 1066.2 & & 696.0 & \\
\hline AIC & -1430.7 & & -1255.4 & & -1919.9 & & -1237.6 & & -2062.4 & & -1348.0 & \\
\hline LR Test & 181.3 & & $\mathrm{p}<0.001$ & & 708.3 & & $\mathrm{p}<0.001$ & & 740.4 & & $\mathrm{p}<0.001$ & \\
\hline Rsq. within & 0.6388 & & 0.5873 & & 0.3468 & & 0.2334 & & 0.5833 & & 0.5170 & \\
\hline Rsq. between & 0.0051 & & 0.0052 & & 0.0008 & & 0.0004 & & 0.1530 & & 0.1341 & \\
\hline $\mathrm{s}_{\mathrm{u}}^{2} /\left(\mathrm{s}^{2}{ }_{\mathrm{u}}+\mathrm{s}_{\mathrm{e}}{ }_{\mathrm{e}}\right)$ & 0.9950 & & 0.9802 & & 0.9816 & & 0.9745 & & 0.9643 & & 0.9852 & \\
\hline
\end{tabular}


Table 4: Mean Absolute Percentage Error (MAPE) and MAPE- Rescaled (MAPE-R)

\begin{tabular}{|c|c|c|c|}
\hline & Burkina Faso & Mali & Niger \\
\hline \multicolumn{4}{|l|}{ Full sample } \\
\hline \multirow[t]{2}{*}{ Obs } & 900 & 3,093 & 3,408 \\
\hline & 2.10 & 2.91 & 3.11 \\
\hline \multirow[t]{2}{*}{ with NDVI } & (1.69) & (2.24) & (2.67) \\
\hline & 2.28 & 3.40 & 3.37 \\
\hline \multirow[t]{2}{*}{ without NDVI } & (1.85) & (2.95) & (2.90) \\
\hline & 0.18 & 0.49 & 0.26 \\
\hline Difference $^{\mathrm{a}}$ & $(0.16)$ & $(0.71)$ & $(0.23)$ \\
\hline $\begin{array}{l}\text { Use of NDVI leads to } \\
\text { a lower error } \\
\text { In sample ( } 80 \%)\end{array}$ & $59 \%$ of the time & $\begin{array}{l}67 \% \text { of the } \\
\text { time }\end{array}$ & $\begin{array}{l}56 \% \text { of the } \\
\text { time }\end{array}$ \\
\hline \multirow[t]{2}{*}{ Obs } & 740 & 2,481 & 2,709 \\
\hline & 2.07 & 2.91 & 3.11 \\
\hline \multirow[t]{2}{*}{ with NDVI } & (1.81) & $(2.25)$ & (2.67) \\
\hline & 2.22 & 3.41 & 3.35 \\
\hline \multirow[t]{2}{*}{ without NDVI } & (1.93) & (2.95) & $(2.85)$ \\
\hline & 0.1538 & 0.49 & 0.24 \\
\hline Difference $^{\mathrm{a}}$ & $(0.12)$ & $(0.70)$ & $(0.18)$ \\
\hline \multicolumn{4}{|l|}{ Out of sample (20\%) } \\
\hline \multirow[t]{2}{*}{ Obs } & 160 & 612 & 699 \\
\hline & 2.34 & 3.00 & 3.22 \\
\hline \multirow[t]{2}{*}{ with NDVI } & $(1.82)$ & $(2.31)$ & (2.77) \\
\hline & 2.55 & 3.51 & 3.50 \\
\hline \multirow[t]{2}{*}{ without NDVI } & (1.93) & $(3.04)$ & $(3.02)$ \\
\hline & 0.21 & 0.51 & 0.28 \\
\hline Difference $^{a}$ & $(0.11)$ & $(0.72)$ & $(0.25)$ \\
\hline
\end{tabular}

Regional regression by country, full sample

$\begin{array}{llll}\text { Obs } & 274 & 680 & 609 \\ & 1.60 & 2.99 & 2.59 \\ \text { with NDVI } & (1.25) & (2.37) & (2.26)\end{array}$

Regional regression estimated jointly, full sample

\begin{tabular}{llll} 
Obs & 1,563 & 1,563 & 1,563 \\
& 2.32 & 3.35 & 3.33 \\
with NDVI & $(1.76)$ & $(2.89)$ & $(3.11)$ \\
\hline
\end{tabular}

a: Predictions significantly different based on Wilcoxon signed-rank test

Table 5: Prediction error for iterative procedure 


\section{Table 5A: Burkina Faso}

Initial training period: January 1995 to July 1998 (70\% of data). Predictions made from November 1998 to December 1999.

\begin{tabular}{|c|c|c|c|c|}
\hline NDVI & Aid & $\begin{array}{l}\text { MSE / } \\
\text { RMSE }\end{array}$ & $\begin{array}{l}\text { Mean \% } \\
\text { error } \\
\text { (MAPE-R) }\end{array}$ & $\begin{array}{l}\text { Mean \% } \\
\text { error of } \\
\text { antilogs }\end{array}$ \\
\hline Yes & Yes & $\begin{array}{l}0.14469187 \\
0.38038385\end{array}$ & $\begin{array}{l}6.77 \\
(6.14)\end{array}$ & 39.14 \\
\hline Yes & No & $\begin{array}{l}0.13909427 \\
0.37295345\end{array}$ & $\begin{array}{l}6.40 \\
(5.47)\end{array}$ & 34.87 \\
\hline No & Yes & $\begin{array}{l}0.07076424 \\
0.26601549\end{array}$ & $\begin{array}{l}4.81 \\
(4.43)\end{array}$ & 26.13 \\
\hline No & No & $\begin{array}{l}0.11617902 \\
0.34085043\end{array}$ & $\begin{array}{l}6.35 \\
(6.06)\end{array}$ & 36.24 \\
\hline
\end{tabular}




\section{Table 5B: Mali}

Initial training period: January 1995 to March 1999 (70\% of data). Predictions made from July 1999 to January 2001.

\begin{tabular}{|c|c|c|c|c|}
\hline NDVI & Aid & $\begin{array}{l}\text { MSE / } \\
\text { RMSE }\end{array}$ & $\begin{array}{l}\text { Mean \% } \\
\text { error }\end{array}$ & $\begin{array}{l}\text { Mean \% } \\
\text { error of } \\
\text { antilogs }\end{array}$ \\
\hline Yes & Yes & $\begin{array}{l}1.8275241 \\
1.3518595\end{array}$ & $\begin{array}{l}20.54 \\
(10.17)\end{array}$ & 341.03 \\
\hline Yes & No & $\begin{array}{l}0.2294739 \\
0.47903434\end{array}$ & $\begin{array}{l}8.54 \\
(6.73)\end{array}$ & 52.59 \\
\hline No & Yes & $\begin{array}{l}0.29280016 \\
0.54111012\end{array}$ & $\begin{array}{l}9.95 \\
(8.43)\end{array}$ & 63.25 \\
\hline No & No & $\begin{array}{l}0.53051891 \\
0.72836729\end{array}$ & $\begin{array}{l}13.41 \\
(11.31)\end{array}$ & 99.53 \\
\hline
\end{tabular}




\section{Table 5C: Niger}

Initial training period: January 1995 to March 2003 (70\% of data). Predictions made from July 2003 to October 2006.

\begin{tabular}{|l|c|c|c|c|}
\hline NDVI & Aid & \multicolumn{1}{|c|}{ MSE / } & \multicolumn{1}{|c|}{ Mean \% } & \multicolumn{1}{|l|}{ Mean \% } \\
& & RMSE & error & error of \\
& & & & antilogs \\
\hline Yes & Yes & 0.20376553 & 7.04 & 45.31 \\
& & 0.45140396 & $(5.21)$ & \\
\hline Yes & No & 0.18953197 & 7.09 & 44.06 \\
& & 0.43535269 & $(5.81)$ & \\
\hline No & Yes & 0.21401535 & 7.41 & 47.40 \\
& & 0.46261793 & $(5.69)$ & \\
\hline No & No & 0.2007883 & 7.61 & 46.64 \\
& & 0.46261793 & $(6.50)$ & \\
\hline
\end{tabular}




\section{Figure 1: Food aid 1988-2009}
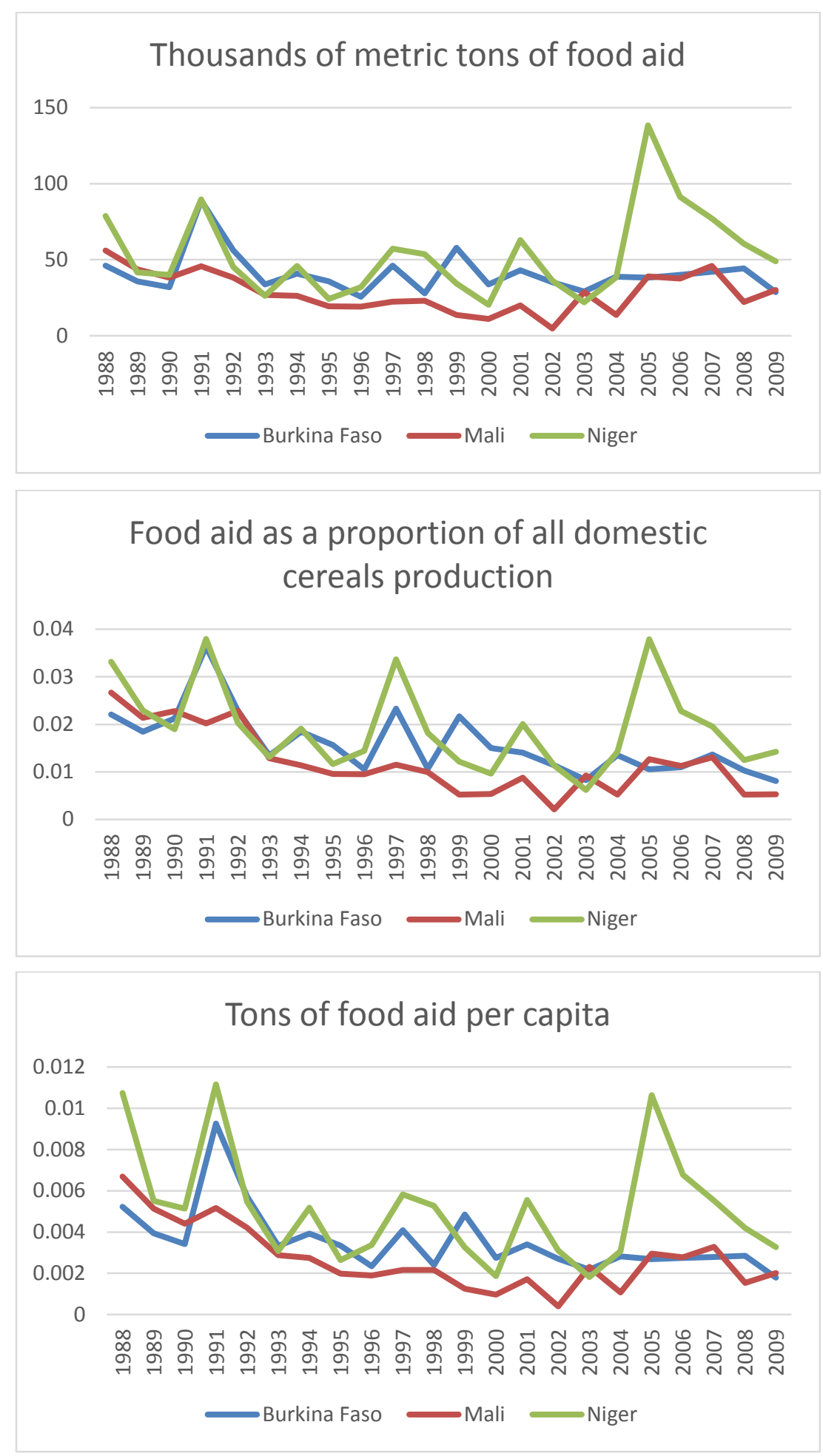
Figure 2: Cereal imports ${ }^{\text {a }}$ 1982-2006 into Burkina Faso, Mali and Niger
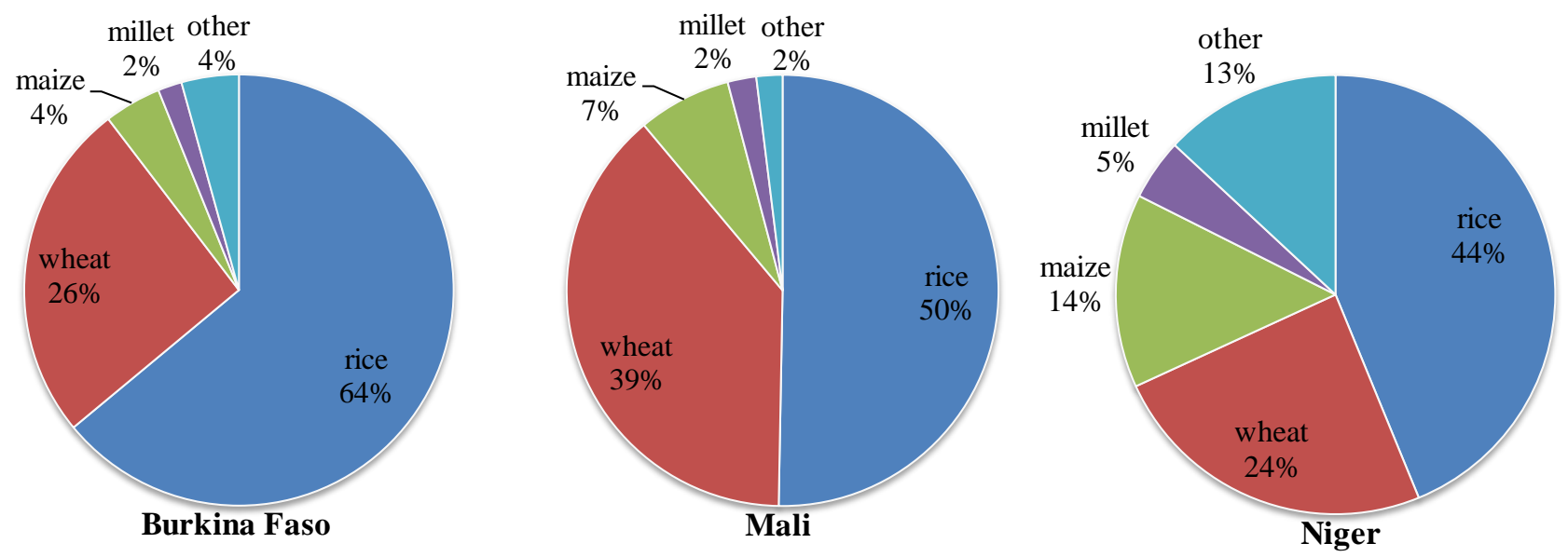

a: Data from FAO 
Figure 3: Average millet prices in 1995-2006 by country

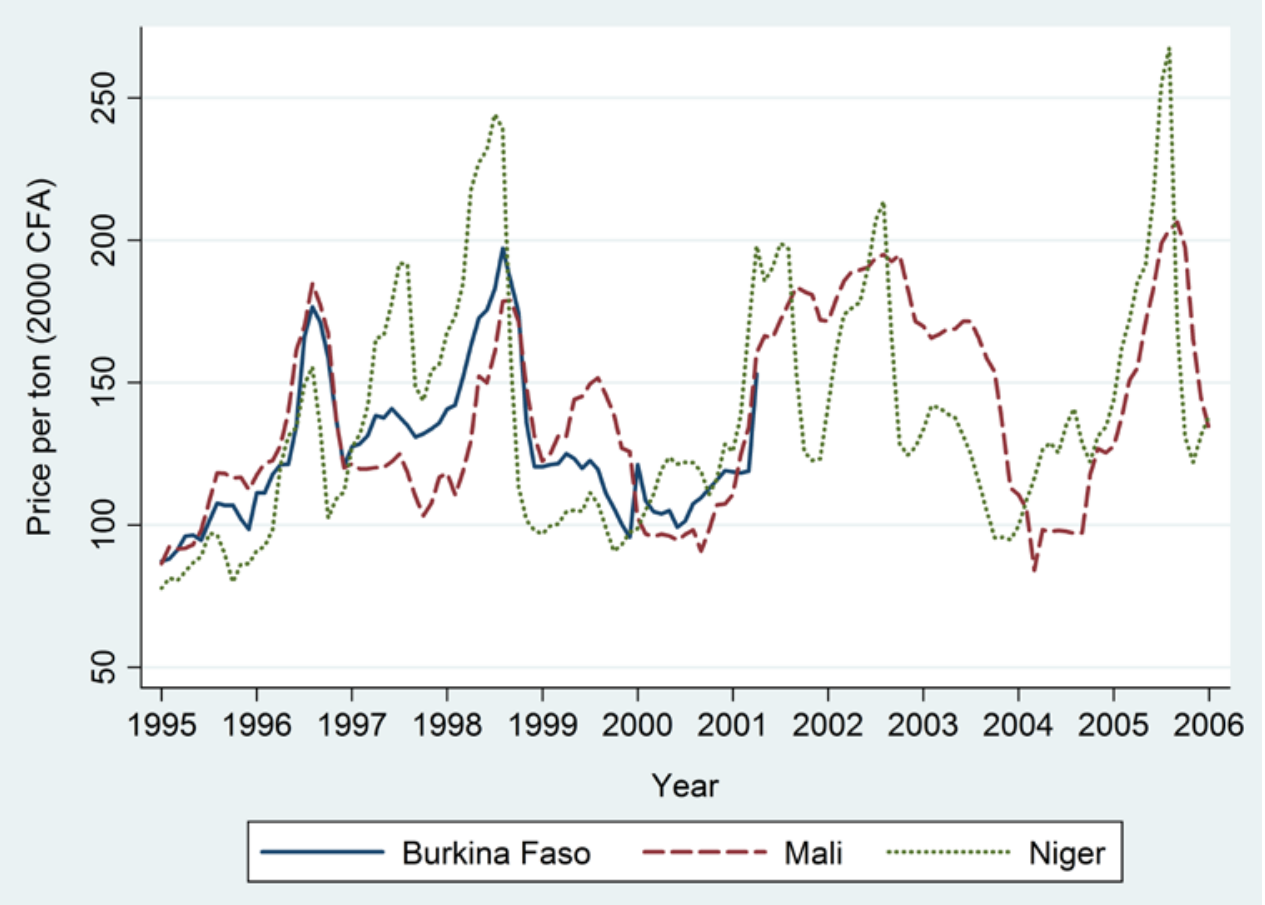


Figure 4: Millet production ${ }^{\mathrm{a}}$ and NDVI ${ }^{\mathrm{b}}$ on the country level, 1982-2006
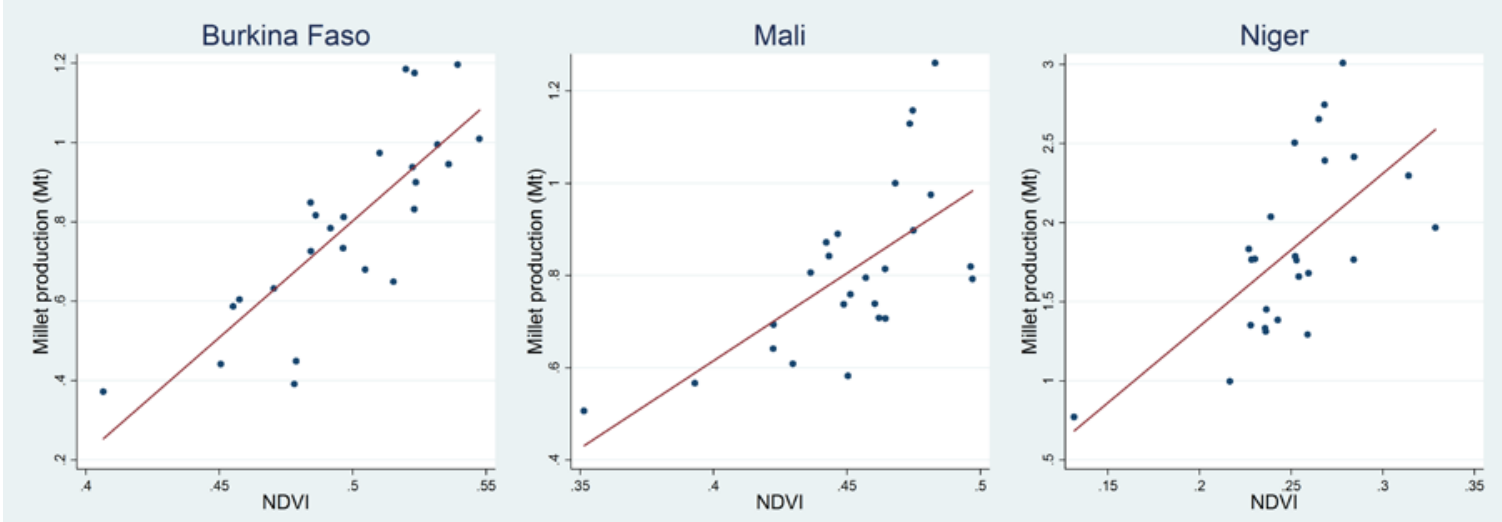

a: Annual data from FAO; b: NDVI represents the maximum during the growing season 
Figure 5: Average monthly millet prices by country, 1995-2006

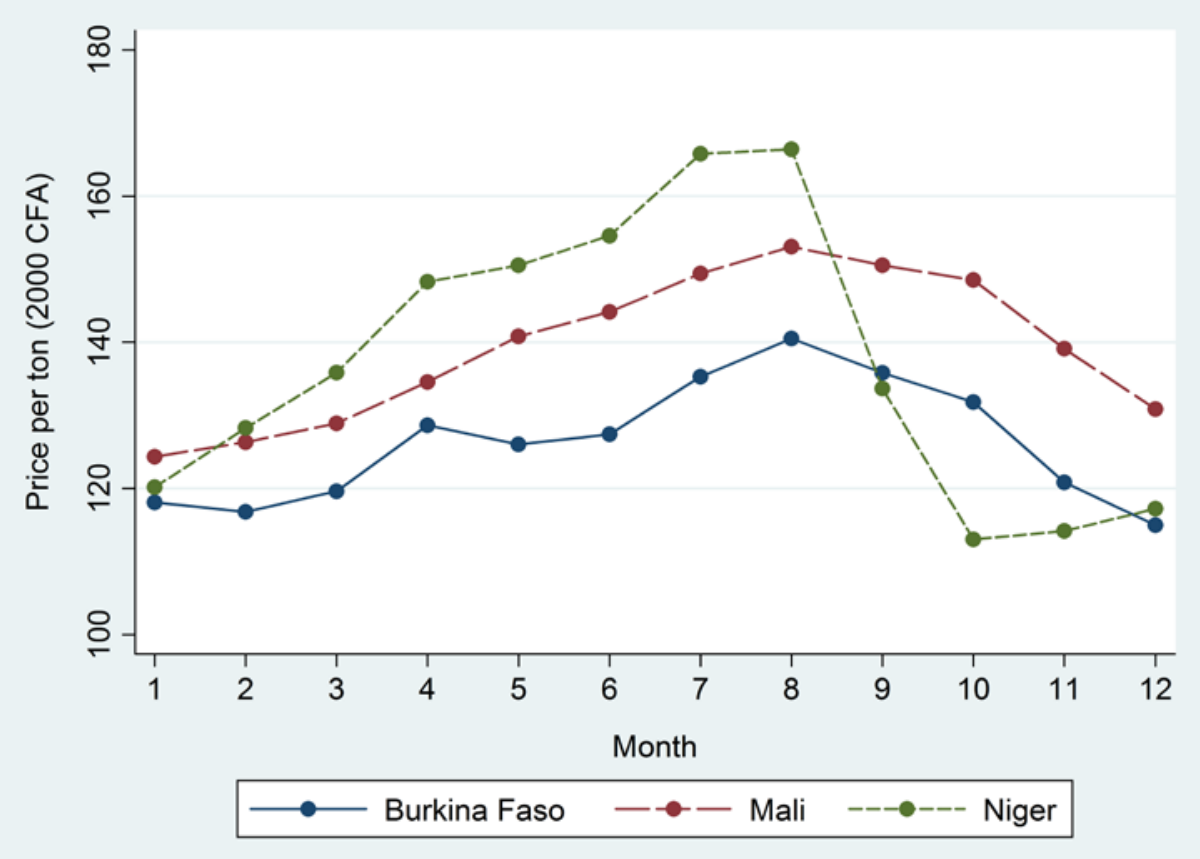


Figure 6: Prediction in-sample vs. out of sample (all values in constant CFA/kg)
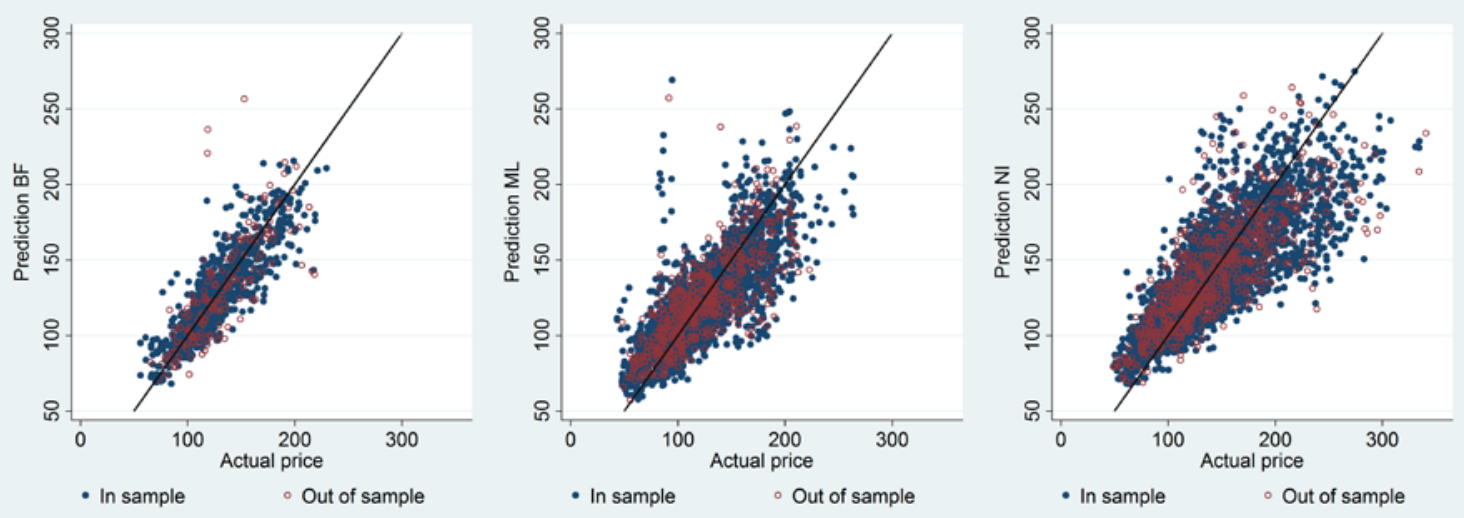
Figure 7: Average prices and 4-month predictions for Burkina Faso.

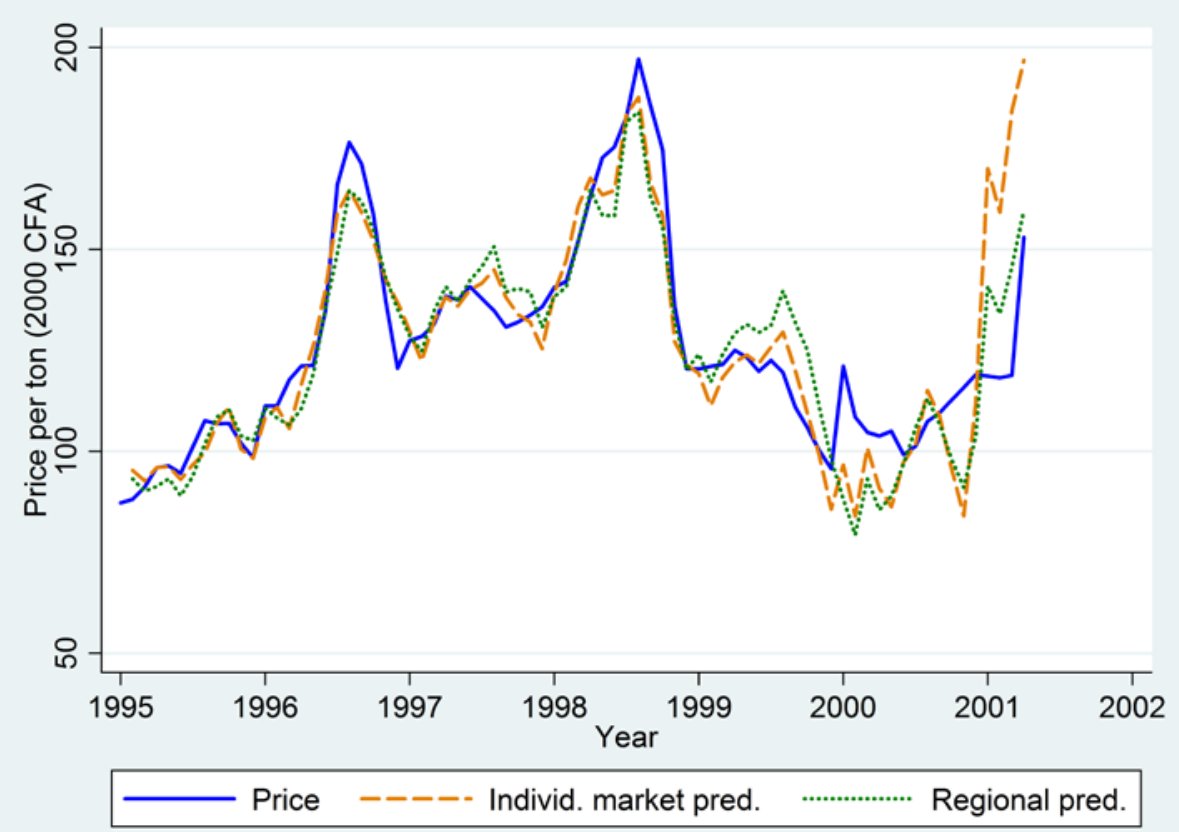

Figure 8: Average prices and 4-month predictions for Mali.

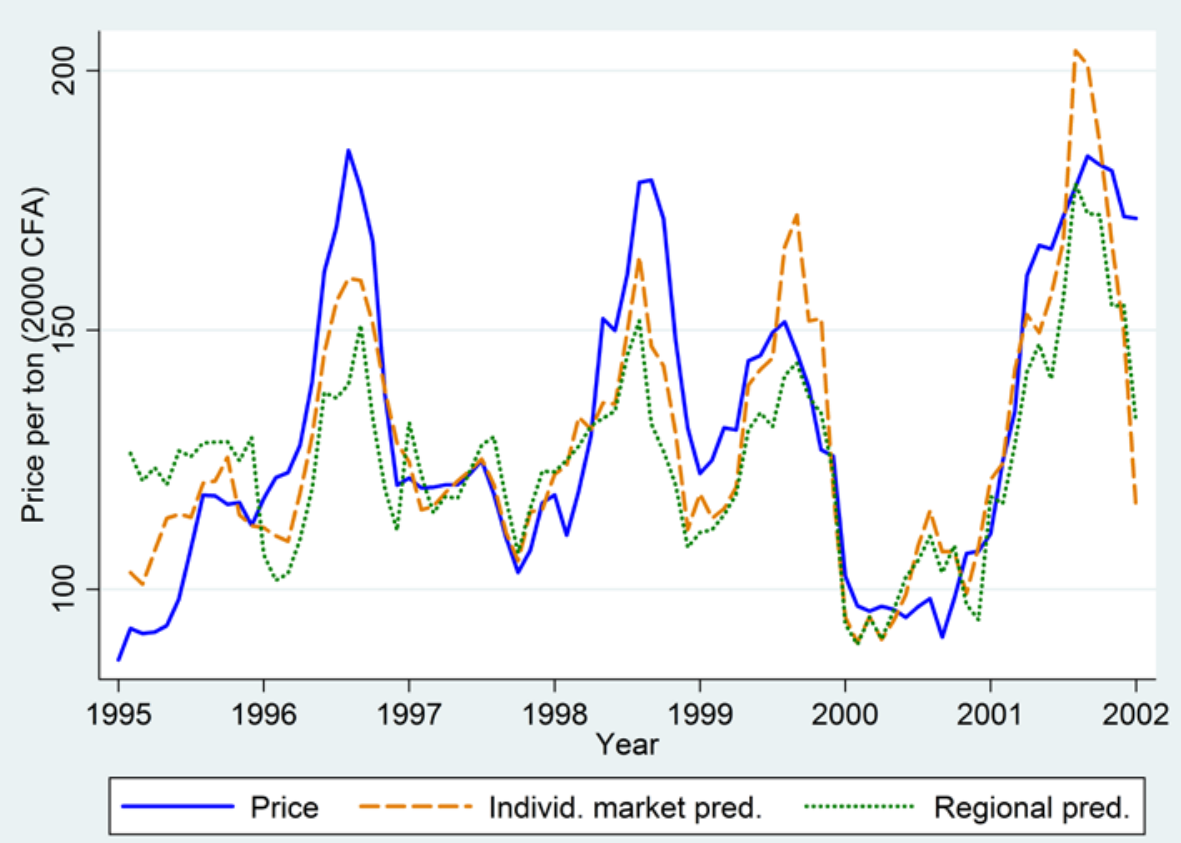


Figure 9: Average prices and 4-month predictions for Niger.

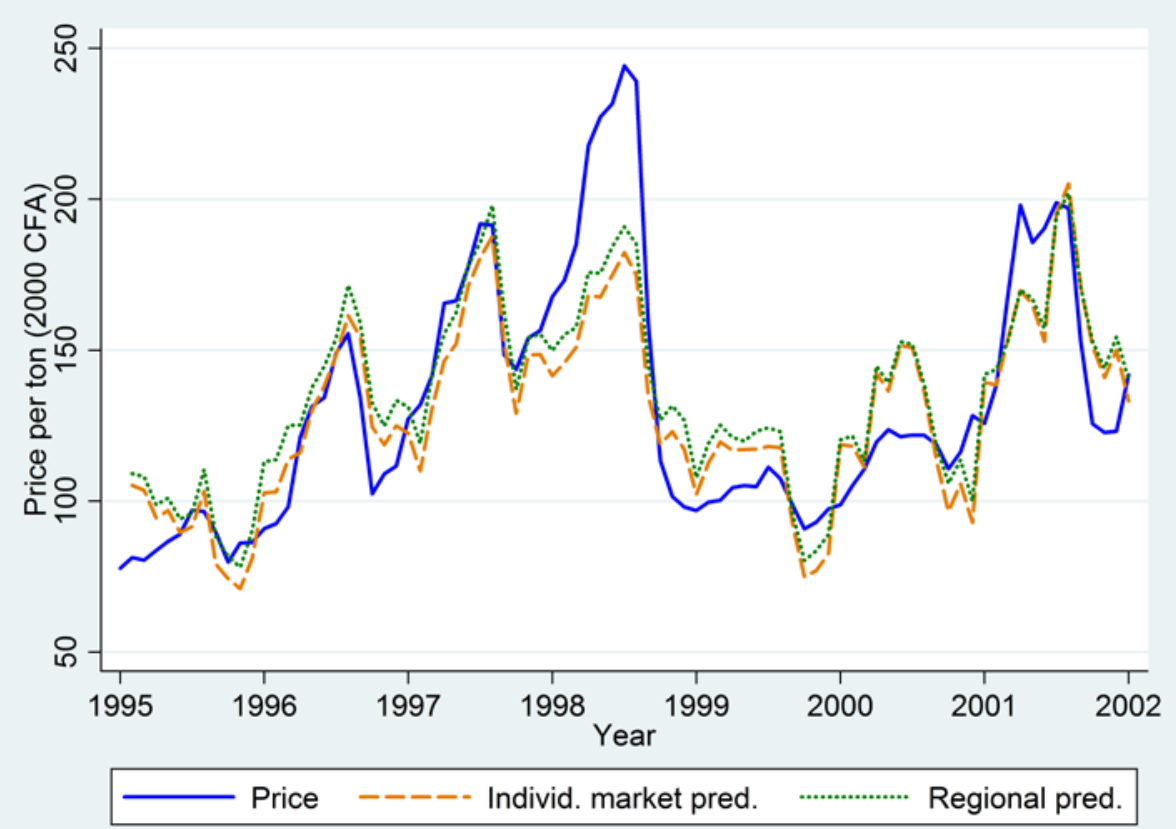




\section{References}

Abdulai, A., CroleRees, A., 2001. Determinants of income diversification amongst rural households in Southern Mali. Food Policy 26, 437-452.

Allen, T., 1998. From 'informal sectors' to 'real economies': changing conception of Africa's hidden livelihoods. Contemporary politics 4, 357-373.

Baker, R.D., 2003. Millet Production, Guide A-414. New Mexico State University, College of Agriculture and Home Economics, Las Cruces, NM. .

Barrett, C.B., Maxwell, D.G., 2005. Food Aid after Fifty Years: Recasting its Role. Routledge, New York.

Basnyat, P., McConkey, B., Lafond, G.R., Moulin, A., Pelcat, Y., 2004. Optimal time for remote sensing to relate to crop grain yield on the Canadian Prairies. Canadian Journal of Plant Science 84, 311-326.

Beekhuis, G., Laouali, I., 2007. Cross-border trade and food markets in Niger: Why market analysis is important for humanitarian action, Humanitarian Exchange Magazine. Humanitarian Practice Network at the Overseas Development Institute (ODI), London.

Breman, H., 2003. West Africa's Subsistence Farming. Food and Agriculture Organization, Rome, Togo, p. 16.

Brown, M.E., 2008. Famine Early Warning Systems and Remote Sensing Data. Springer Verlag, Heidelberg.

Brown, M.E., Brickley, E.B., 2012. Evaluating the Use of Remote Sensing data in the USAID Famine Early Warning Systems Network. Journal of Applied Remote Sensing 6, 063511.

Brown, M.E., Hintermann, B., Higgins, N., 2009a. Markets, Climate Change and Food Security in West Africa. Environmental Science and Technology 43, 8016-8020.

Brown, M.E., Hintermann, B., Higgins, N., 2009b. Markets, Climate Change, and Food Security in West Africa. Environmental Science \& Technology, in Press. .

Brown, M.E., Pinzon, J.E., Prince, S.D., 2006. The Sensitivity of Millet Prices to Vegetation Dynamics in the Informal Markets of Mali, Burkina Faso and Niger. Climatic Change 78, 181-202.

Bryceson, D.F., 2002. The Scramble in Africa: Reorienting Rural Livelihoods. World Development 30, 725-739.

Buchanan-Smith, M., Davies, S.M., 1995. Famine Early Warning and Response. IT Press.

Cekan, J., 1992. Seasonal Coping Strategies in Central Mali: Five Villages During the 'Soudure'. Disasters 16, 66-73. 
Choi, I., 2001. Unit Root Tests for Panel Data. Journal of International Money and Finance 20, 249-272.

Chopak, C., 1999. Price Analysis for Early Warning Monitoring and Reporting. FEWS, Harare, Zimbabwe, p. 78.

Dembele, N.N., Staatz, J., 1999. The response of Cereal Traders to Agricultural Market Reform in Mali. Michigan State University, East Lansing, MI, p. 18.

Dorosh, P.A., Subran, L., 2009. Food Aid, External Trade and Domestic Markets: Implications for Food Security in Darfur, Contributed paper for presentation at the International Association of Agricultural Economists Conference, Beijing.

FAIS, 2014. World Food Aid Flows. UN World Food Program.

Fuller, D.O., 1998. Trends in NDVI time series and their relation to rangeland and crop production in Senegal, 1987-1993. International Journal of Remote Sensing 19, 2013-2018.

Funk, C.C., Brown, M.E., 2006. Intra-seasonal NDVI change projections in semi-arid Africa. Remote Sensing of Environment 101, 249-256.

Godfrey, L.G., Wickens, M.R., 1981. Testing Linear and Log-Linear Regressions for Functional Form. Review of Economic Studies XLVIII, 487-496.

Holben, B., 1986. Characteristics of Maximum-Value Composite Images from Temporal AVHRR Data. International Journal of Remote Sensing 7, 1417-1434.

IMF, 2013. West African Economic and Monetary Union (WAEMU): Staff Report on Common Policies for Member Countries, IMF Country Report No 13/92. International Monetary Fund, Washington DC, p. 106.

Jiang, D., Yang, X., Clinton, N., Wang, N., 2004. An artificial neural network model for estimating crop yields using remotely sensed information. International Journal of Remote Sensing 25, 1723-1732.

Justice, C.O., Dugdale, G., Townshend, J.R.G., Narracott, A.S., Kumar, M., 1991. Synergism Between NOAA-AVHRR and Meteosat Data for Studying Vegetation Development in Semi-arid West Africa. International Journal of Remote Sensing 12, 1349-1368.

Kelly, V., Dembele, N.N., Staatz, J., 2008. Potential Food Security Impacts of Rising Commodity Prices in the Sahel: 2008-2009. Famine Early Warning Systems Network (FEWS NET), USAID and Michigan State University, p. 50 p.

Maddala, G.S., Wu, S., 1999. A Comparative Study of Unit Root Tests with Panel Data and a New Simple Test. Oxford Bulletin of Economics and Statistics 61, 631-652.

Maselli, F., Conese, C., Petkov, L., Gilabert, M.A., 1993. Environmental Monitoring and Crop Forecasting in the Sahel through the use of NOAA NDVI data. A case study: Niger 1986-1989. International Journal of Remote Sensing 14, 3471-3487. 
Maselli, F., Romanelli, L., Bottai, L., Maracchi, G., 2000. Processing of GAC NDVI data for yield forecasting in the Sahelian region. International Journal of Remote Sensing 21, 3509-3523.

May, C.A., 1991. Update Report to USAID/N'Djamena on the Market Information System (SIM) in Chad. FEWS, Washington, p. 86.

Nicholson, S.E., 1994. On the use of the Normalized Difference Vegetative Index as an indicator of rainfall, in: Desbois, M., Desalmand, F. (Eds.), Global Precipitations and Climate Change. NATO ASI Series, Berlin, pp. 293-305.

Prince, S.D., 1991. Satellite Remote Sensing of Primary Production: Comparison of Results for Sahelian Grasslands. International Journal of Remote Sensing 12, 13011311.

Rasmussen, M.S., 1992. Assessment of millet yields and production in northern Burkina Faso using integrated NDVI from the AVHRR. International Journal of Remote Sensing 13, 3431-3442.

Rasmussen, M.S., 1997. Operational Yield Forecast using AVHRR NDVI data: Reduction of Environmental and Inter-Annual Variability. International Journal of Remote Sensing 18, 1059-1077.

Rasmussen, M.S., 1998a. Developing simple, operational, consistent NDVI-vegetation models by applying environmental and climatic information: Part I. Assessment of net primary production. International Journal of Remote Sensing 19, 97-117.

Rasmussen, M.S., 1998b. Developing simple, operational, consistent NDVI-vegetation models by applying environmental and climatic information. Part I: Assessment of net primary production. International Journal of Remote Sensing 19, 97-119.

Sargan, J.D., 1964. Wages and Prices in the United Kingdom, in: Hart, P.E., Mills, G., Whitaker, J.K. (Eds.), Econometric Analysis for National Economic Planning. Butterworths, London, p. 320.

Swinnen, J., 2011. The Right Price of Food. Development Policy Review, 29(6): 667688.

Taylor, J.E., Lambin, E.F., Stephenne, N., Harding, R.J., Essery, R.L.H., 2002. The influence of land use change on climate in the Sahel. Journal of Climate 15, 36153629.

Terpend, N., 2006. An Assessment of knowledge about trade and markets related to food security in West Africa. United Nations World Food Program Rome, Italy.

Townshend, J.R.G., 1994. Global Data Sets for Land Applications from the Advanced Very High Resolution Radiometer: An Introduction. International Journal of Remote Sensing 15, 3319-3332.

Tucker, C.J., 1979. Red and Photographic Infrared Linear Combinations for Monitoring Vegetation. Remote Sensing of Environment 8, 127-150. 
Tucker, C.J., Holben, B.N., Elgin, J.H., McMurtrey, 1981. Remote sensing of total dry matter accumulation in winter wheat. Remote Sensing of Environment 11, 171.

Tucker, C.J., Pinzon, J.E., Brown, M.E., Slayback, D., Pak, E.W., Mahoney, R., Vermote, E., El Saleous, N., 2005. An Extended AVHRR 8-km NDVI Data Set Compatible with MODIS and SPOT Vegetation NDVI Data. International Journal of Remote Sensing 26, 4485-4498.

Tucker, C.J., Vanpraet, C. L., Sharman, M. J. and van Ittersum, G., 1985. Satellite Remote Sensing of Total Herbaceous Biomass Production in the Senegalese Sahel: 19801984. Remote Sensing of Environment 17, 233-249.

Verdin, J., Funk, C., Senay, G., Choularton, R., 2005. Climate science and famine early warning. Philosophical Transactions of the Royal Society B: Biological Sciences 360, 2155 - 2168.

WorldBank, 2014. Doing Business 2014 Regional Profile: Sub-Saharan Africa (SSA), Understanding Smarter Regulations for Small and Medium-Size Enterprises. . The World Bank, Washington DC.

Yu, B., You, L., Fan, S., 2009. A Typology of Food Security in Developing Countries under High Food Prices, Contributed paper for presentation at the International Association of Agricultural Economists Conference, Beijing. 